\title{
New methods for in vivo studies of hepatic metabolism
}

\author{
M Beylot, O Peroni, F Diraison, V Large \\ Unité 197 de l'Inserm, faculté de médecine René-Laënnec, rue Guillaume-Paradin, \\ 69372 Lyon cedex 08, France
}

(Received 29 November 1995; accepted 6 May 1996)

\begin{abstract}
Summary — In vivo studies of liver metabolism have been limited for a long time to measurements, by the balance technique or the isotope dilution method, of the amounts of substrates taken up or produced by liver. New methods have been developed that now permit us to obtain important information on intrahepatic metabolic pathways. Nuclear magnetic resonance permits noninvasive studies of liver glycogen synthesis and breakdown. Chemical biopsy of glucuronic acid by acetaminophen also permits the study of glycogen synthesis whereas chemical biopsies of liver glutamine by phenylacetate and of cytosolic acetyl-CoA by sulfamethoxazole give important information concerning, respectively, Krebs cycle activity and gluconeogenesis and on lipogenesis and cholesterol synthesis. Mass isotopomer distribution analysis of molecules synthesized during the infusion of a deuterium or ${ }^{13} \mathrm{C}$ labeled precursor permits the estimation of in vivo gluconeogenesis as well as cholesterol synthesis and lipogenesis. Finally, these metabolic pathways can be studied through the incorporation of deuterium from deuterated water in glucose, fatty acids and cholesterol. All these noninvasive techniques will allow investigations to be undertaken in humans, addressing the nutritional and hormonal regulation of liver metabolism in normal subjects and in pathological situations.
\end{abstract}

\section{chemical biopsy / stable isotopes / gluconeogenesis / lipogenesis / cholesterol synthesis}

Résumé - Nouvelles méthodes d'étude in vivo du métabolisme hépatique. L'étude in vivo du métabolisme hépatique a longtemps été limitée aux mesures, par dilution isotopique ou par balance splanchnique, des quantités de substrats captés ou libérés par le foie. De nouvelles méthodes permettent maintenant d'obtenir, de manière peu ou pas agressive, des informations importantes sur le métabolisme intrahépatique. La résonance magnétique nucléaire permet d'étudier la synthèse et la dégradation du glycogène. La biopsie chimique de l'acide glucuronique par l'acétominophène étudie également la synthèse de glycogène tandis que les biopsies de la glutamine (par le phénylacétate) et de l'acétylCoenzyme A cytosolique (par le sulfamethoxazole) hépatique pemettent respectivement d'étudier l'activité du cycle de Krebs et de la néoglucogenèse, et celle de la lipogenèse et de la synthèse de cholestérol. L'analyse de la distribution des isotopomères des molécules synthétisées durant la perfusion de précurseurs marqués par du deutérium ou du ${ }^{13} \mathrm{C}$ donne accès à des mesures de la néoglucogenèse, de la lipogenèse et de la synthèse de cholestérol. Enfin, l'activité de ces voies métaboliques peut être mesurée par l'incorporation dans le glucose, les acides gras et le cholestérol de deuterium 
à partir d'eau deutérée. Toutes ces méthodes permettent l'étude de la régulation nutritionnelle et hormonale du métabolisme hépatique chez le sujet normal et sa pathologie.

biopsie chimique / isotopes stables / néoglucogenèse / lipogenèse / synthèse de cholestérol

\section{INTRODUCTION}

The liver plays a central role in metabolic regulation, particularly when considering glucose and lipid metabolism. With respect to glucose, the liver stores glucose as glycogen after meals and produces glucose in the postabsorptive state and during starvation through first glycogenolysis and then gluconeogenesis. In lipid metabolism, the liver oxidizes fatty acids completely to $\mathrm{CO}_{2}$ or partially to ketone bodies. It is also capable of lipogenesis. It synthesizes triglycerides (TG) using the fatty acids taken up from plasma or synthesized in situ. These TG are then exported to extrahepatic tissues incorporated along with apoproteins, phospholipids and cholesterol into very low density lipoproteins (VLDL). Finally, the liver is responsible for a large part of the body's cholesterol synthesis.

The in vivo exploration in humans of these multiple and complex metabolic pathways has been mainly limited to the measurements of the amounts of metabolites taken up or produced by the liver, using either tracer methodology or the splanchnic balance technique. Despite some methodologies using the simultaneous infusion of several tracers to obtain insights into hepatic metabolism (Shulman et al, 1985; Beylot et al, 1991), most of the aspects of intrahepatic metabolic pathways have eluded investigation. This frustrating situation is being resolved as the development of new methods and the amelioration of older ones now permit the noninvasive exploration of more aspects of hepatic metabolism. This review will focus on these new aspects of the research on hepatic glucose and lipid metabolisms and will describe the principles behind and some applications of four methodologies: new nuclear magnetic resonance (NMR), chemical biopsy, mass isotopomer distribution analysis (MIDA) and deuterium incorporation from deuterated water. All these methods rely on the use of stable isotopes and can be safely used in humans.

\section{NUCLEAR MAGNETIC RESONANCE (NMR)}

${ }^{13} \mathrm{C}$ NMR has long been used for metabolic investigations (Schulman et al, 1979) and technical improvements now allow its use in liver as well as muscle metabolism studies in humans. These studies take advantage of the ability of NMR to measure the abundance of ${ }^{13} \mathrm{C}$ in organic molecules. However, given the low natural abundance of ${ }^{13} \mathrm{C}(1.1 \%)$ and the low sensitivity of NMR, this requires either a high concentration of the organic molecule studied or an increase of the ${ }^{13} \mathrm{C}$ abundance in this molecule through the intravenous infusion or oral ingestion of a ${ }^{13} \mathrm{C}$-labeled tracer. The first condition (sufficiently high concentration) is fulfilled by liver glycogen (except when glycogen stores are depleted by prolonged fasting) and the resonance from the C-1 glycosyl units in liver glycogen has been used to follow the progressive decrease in glycogen level during fasting in control subjects and type II diabetic patients (Petersen et al, 1966; Rothman et al, 1991; Magnusson et al, 1992). Liver volume was also measured by NMR imaging, thus making it possible to calculate the rate of glucose production from 
glycogenolysis. Gluconeogenesis was next calculated by substracting glycogenolysis from total glucose production measured by the isotope dilution technique. Using this method, it was found that gluconeogenesis, expressed as the absolute value or percentage of glucose production, was increased in type II diabetes (Magnusson et al, 1992). NMR can also be used to follow, after administration of a ${ }^{13} \mathrm{C}$-labeled tracer, the appearance and distribution of the excess ${ }^{13} \mathrm{C}$ in intrahepatic metabolites (Stromski et al, 1986) as well as in hepatic metabolites sampled using the chemical biopsy techniques (see later) (Dugelay et al, 1994; Hwang et al, 1995; Roden et al, 1996). This has been used to measure the liver glycogen turnover in human subjects (Magnusson et al, 1994; Roden et al, 1996) and the metabolic pathways used for glycogen repletion after feeding (Hwang et al, 1995; Roden et al, 1996). Thus, NMR is a useful tool for in vivo studies of liver metabolism; it has the advantage of being noninvasive; however, the need for expensive equipment and, except for measures of glycogen content, large doses of ${ }^{13} \mathrm{C}$ labeled tracers limits its use.

\section{CHEMICAL BIOPSY}

When liver metabolic pathways such as gluconeogenesis or lipogenesis are traced in vivo using the infusion of a labeled precursor (eg, lactate or acetate) the enrichment of this precursor is measured in peripheral blood. There are two major drawbacks to this technique: i) this enrichment may be higher than the enrichment in portal venous blood and inside the liver (Large et al, 1995) and ii) some label may be lost through metabolic exchanges during intrahepatic metabolism (this is especially the case when labeled carbons from lactate, pyruvate or alanine cross the oxaloacetate pool on their way to phosphoenolpyruvate) (Hetenyi,
1982). These successive dilutions result in some error if no correction is made to the classical calculation of metabolic flux using the product over precursor enrichment ratio. Chemical biopsy is one way to overcome these limitations. This method, which was mainly developed by Hellerstein and Landau, takes advantage of the ability of some compounds, natural or xenobiotic, to bind with metabolites inside the liver. The conjugate returns to the circulation where it can then be sampled. It is thus possible to obtain information during the infusion of labeled tracers on the enrichment and the distribution of the label in intrahepatic metabolites.

Three main applications of this chemical biopsy have been developed (fig 1). The first uses the ability of acetaminophene to bind with glucuronic acid to study glycogen metabolism and the role of direct and indirect pathways in the synthesis of liver glycogen (Hellerstein et al, 1986, 1995; Hwang et al, 1995; Roden et al, 1996). The second uses sulfamethoxazole (SMX) to sample liver cytosolic acetyl-CoA during the infusion of ${ }^{13} \mathrm{C}$-labeled acetate to study lipogenesis (Hellerstein et al, 1991a, b). Using this method, it was estimated that hepatic lipogenesis in normal postabsorptive subjects contributes only $2-4 \%$ to the amount of TG secreted by the liver. Although some data suggesting that SMX samples the true lipogenic pool of acetyl-CoA have been presented (Hellerstein et al, 1991b), this method has been criticized: cytosolic acetyl-CoA can also be sampled using phenylaminobutyrate and paraaminobenzoate and quite different enrichment values of acetyl-CoA were obtained, at least in perfused rat livers (Zhang et al, 1994). Moreover, the enrichments are different depending on whether ${ }^{13} \mathrm{C}$ is introduced as labeled acetate or through the liver metabolism of labeled octanoate or very long chain fatty acids (Zhang et al, 1994). These results are evidence of cytosolic acetyl-CoA compart- 


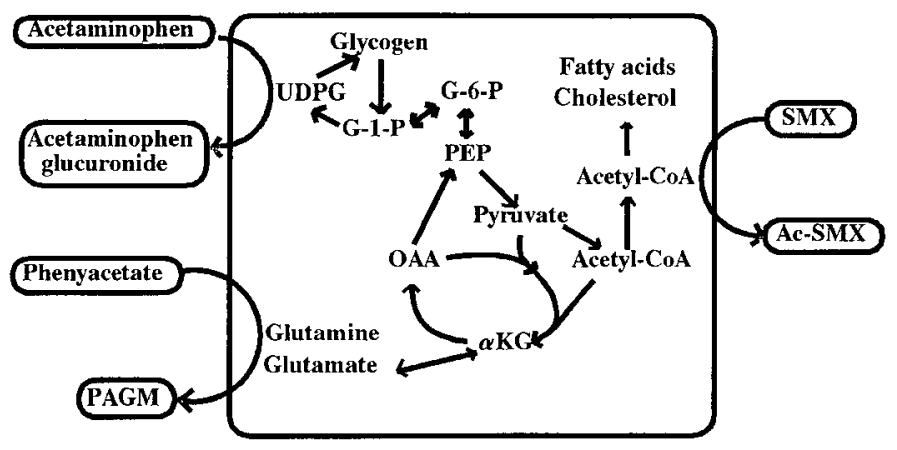

Fig 1. General principles behind the use of chemical biopsies in the liver to study glycogen synthesis (biopsy of glucuronic acid by acetaminophene), lipogenesis and cholesterol synthesis (biopsy of cytosolic acetyl-CoA by sulfamethoxasol [SMX]), Kreb's cycle activity and gluconeogenesis (biopsy of glutamine by phenylacetate).

mentation and suggests that SMX may not only sample the lipogenic pool.

The third application of the chemical biopsy technique takes advantage of the ability of primate livers to conjugate phenylacetate with glutamine (James et al, 1972). The resulting phenylacetylglutamine (PAGM) can then be collected in plasma or urine (Magnusson et al, 1991; Yang et al, 1993). Phenylacetate is an intermediate of phenylalanine metabolism and its concentration can be increased by ingesting phenylalanine (Yang et al, 1993). Liver glutamine equilibrates with glutamate and $\alpha$-ketoglutarate, an intermediate in the Krebs' cycle. During infusion of a ${ }^{13} \mathrm{C}$-labeled tracer, such as lactate or acetate, the distribution of ${ }^{13} \mathrm{C}$ on the five carbons of $\alpha$-ketoglutarate, and thus of glutamate and glutamine, depends on the relative activities of the main enzymes of the Krebs' cycle and of the gluconeogenic pathway (Katz, 1985; Kelleher, 1986; Magnusson et al, 1991). For example, during the infusion of $[3-13 \mathrm{C}]$ lactate, lactate metabolism through pyruvate dehydrogenase (PDH) (oxidation) labels carbon 4 of $\alpha$-ketoglutarate (fig 2) whereas metabolism through pyruvate carboxylase (PC) (first step of gluconeogenesis) labels carbons 2 and 3 . Therefore, the relative labeling of carbons 2 and 3 versus carbon 4 permits the estimation of the PC over PDH activity ratio. Magnusson and Landau (Magnusson et al, 1991) proposed a mathematical model for Krebs' cycle and gluconeogenesis that permits the calculation of the relative activities of Krebs' cycle and gluconeogenesis and of a dilution factor between hepatic lactate and phosphoenolpyruvate from the labeling pattern of liver $\alpha$-ketoglutarate or glutamate (or from the glutamine moiety of PAGM) during the infusion of lactate labeled on carbon 3. They used this method with ${ }^{14} \mathrm{C}$-labeled lactate to estimate gluconeogenesis in fasted normal subjects (Magnusson et al, 1991) and in insulin-dependent diabetics (Landau et al, 1995a). This method can be adapted to ${ }^{13} \mathrm{C}$-labeled tracers since the ${ }^{13} \mathrm{C}$-labeling pattern of glutamate or of the glutamine part of PAGM can be determined by mass spectrometry (Beylot et al, 1993; Di Donato et al, 1993; Yang et al, 1996) or NMR (Dugelay et al, 1994). To test the validity of this model, isolated rat livers were perfused with $[3-13 \mathrm{C}]$ lactate in the absence or presence of glucagon (to inhibit pyruvate kinase), dichloroacetate (to stimulate PDH) or mercaptopicolinate (to inhibit phosphoenolpyruvate carboxykinase PEPCK). The expected modifications of metabolic flux were detected using the labeling pattern of liver glutamate and Magnusson's model (Large et al, 1994). In addition, a comparison of the labeling pattern of liver glutamate between in vitro (perfused liver) and in vivo (rats infused with [3-13 C]lactate) 
studies, supports the validity of this method, provided that a correction for ${ }^{13} \mathrm{CO}_{2}$ reincorporation through $\mathrm{PC}$ in vivo is performed (Beylot et al, 1995). However, this comparison was made only in the fasted state and still needs to be studied in the postabsorptive or fed state. In conclusion, this approach gives important information concerning the Krebs' cycle and gluconeogenesis in the liver. This model does not, however, take into account the dilution of lactate enrichment between the peripheral blood and the liver, nor does it consider the contribution of glycerol to glucose production.

\section{MASS ISOTOPOMER DISTRIBUTION ANALYSIS (MIDA)}

Isotopomers are molecules having the same structure and chemical composition which differ in mass due to the presence of zero, one, two, ... $n$ excess stable isotopes (eg, one, two, three excess ${ }^{13} \mathrm{C}$, resulting in increases of molecular weight of one, two, three mass units). When a molecule is synthesized through the addition of several identical precursors and when this precursor is labeled by stable isotopes, there is a synthesis of molecules having incorporated zero, one, two or more excess stable iso-

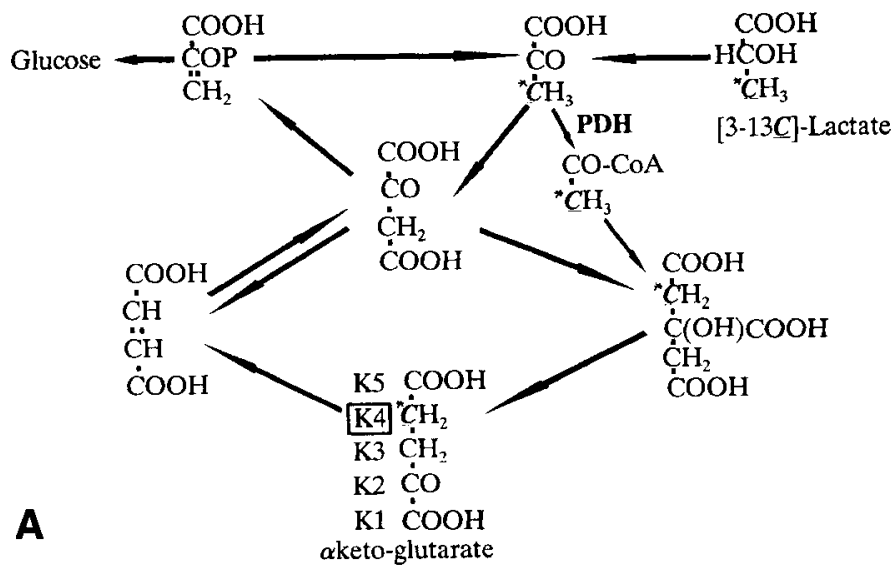

Fig 2. Labeling of hepatic $\alpha$ ketoglutarate by $\left[3-{ }^{13} \mathrm{C}\right]$ lactate depending on the metabolic route followed. Oxidation by pyruvate dehydrogenase (PDH) labels $\mathrm{C}-4$ of $\alpha$-ketoglutarate (A). As a result of the equilibrium between oxaloacetate and the symmetric molecule, fumarate, metabolism by pyruvate carboxylase (PC) labels the $\mathrm{C}-2$ and $\mathrm{C}-3$ of oxaloacetate, then citrate and $\alpha$-ketoglutarate (B).

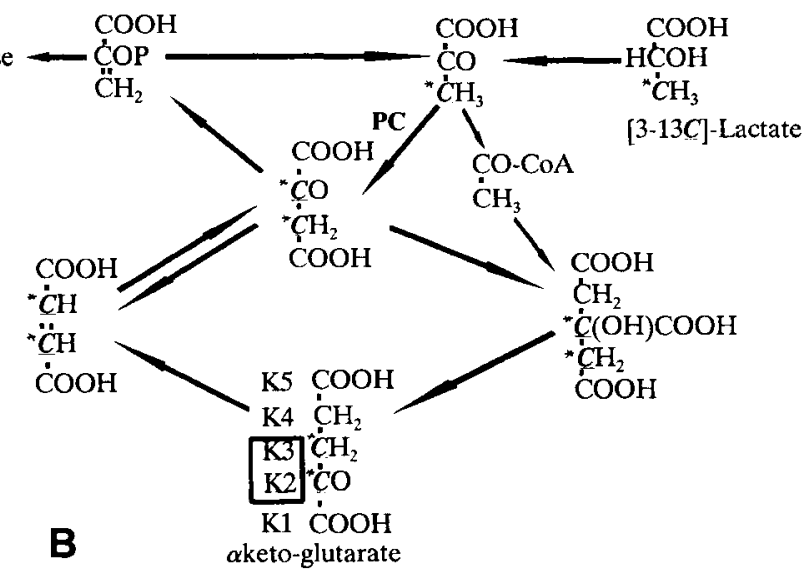


topes. The relative abundance of these different isotopomers in the synthesized product is only a function of the enrichment of the precursor (Hellerstein and Neese, 1992; Kelleher and Masterson, 1992; Lee et al, 1992). This distribution of isotopomers can be analyzed by mass spectrometry and, from this distribution, the enrichment in the precursor and then the fraction of the product that is newly synthesized may be calculated. Gluconeogenesis can be measured using this method since glucose is formed by the addition to two triose-phosphates (TP). When these TP are labeled, with an enrichment $p$, there will be synthesis of glucose having incorporated no labeled TP $\left(g_{0}\right)$, one labeled TP $\left(g_{1}\right)$ or two labeled TP $\left(g_{2}\right)$. If gluconeogenesis is the only source of glucose, the relative abundance (distribution) of these three isotopomers $\left(g_{0}, g_{1}, g_{2}\right)$ is dependent only upon $\mathrm{p}$. If the glucose coming from gluconeogenesis is diluted by unlabeled glucose from glycogenolysis, the proportion of $g_{0}$ (unlabeled glucose) will increase and that of $g_{1}$ and $g_{2}$ (singly and doubly labeled glucose) will decrease. How- ever, the ratio $g_{1} / g_{2}$ remains unchanged as it depends only on p (Hellerstein et al, 1992; Kelleher and Masterson, 1992; Lee et al, 1992; Peroni et al, 1995). This ratio permits the calculation of hepatic TP enrichment and therefore, through the comparison of this enrichment to that of glucose, the calculation of the contribution of gluconeogenesis to glucose production (fig 3 ). This method takes into account all gluconeogenic pathways and overcomes the problems of dilution of precursor enrichment between the peripheral blood and liver. Evidence has been provided (Neese et al, 1995; Peroni et al, 1995, 1996) for the in vitro and in vivo validity of this method for calculating gluconeogenesis when using $\left[2-{ }^{13} \mathrm{C}\right]$ glycerol infusion to label hepatic TP. However, other authors (Landau et al, 1995b; Previs et al, 1995) reported discordant results suggesting that one main condition of validity for this method, the homogeneity of the labeling of the hepatic TP pool, is not always fulfilled. The use of MIDA is not limited to gluconeogenesis; this method can also be used for studies of fatty acids and cholesterol syn-

\section{triose-phosphates glucose}

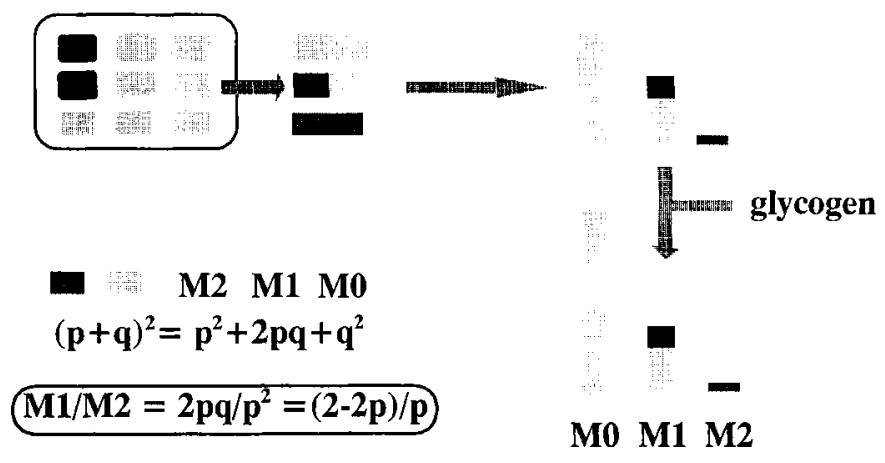

Fig 3. Principles behind using the mass isotopomer distribution analysis (MIDA) method to measure gluconeogenesis. Glucose synthesis from a mixture of labeled triose-phosphates (black squares) having an abundance $p$ and nonlabeled ones (gray squares) having an abundance $q$, produces a mixture of unlabeled glucose ( $\mathrm{MO}$, gray) and glucose labeled with either one ${ }^{13} \mathrm{C}(\mathrm{M} 1$, gray and black) or two ${ }^{13} \mathrm{C}$ (M2, black). The dilution of the glucose originating from gluconeogenesis by unlabeled glucose derived from glycogenolysis does not modify the abundance ratio between M1 and M2. This only depends on the level of $p$ enrichment in the labeled triose-phosphate molecules. Measurement of $\mathrm{M} 1 / \mathrm{M} 2$ thus permits the calculations of the $\mathrm{p}$ enrichment level. 
thesis (Hellerstein et al, 1991b, c; Neese et al, 1993), using ${ }^{13} \mathrm{C}$-labeled acetate to enrich the cytosolic acetyl-CoA pool.

\section{DEUTERIUM INCORPORATION FROM DEUTERATED WATER}

When the total body water is labeled with deuterated water, deuterium is incorporated into the final products of various biosynthetic pathways such as gluconeogenesis, cholesterol and fatty acid synthesis. Deuterium can be incorporated directly from deuterated water or indirectly through $\mathrm{NADH}$ or NADPH or through the previous labeling of precursors such as acetyl-CoA. This enrichment in deuterium of the final products will be all the more high when body water is enriched and the synthetic pathway is active. It can therefore be used to estimate the activity of this pathway. This method dates back to the classic work of Rittenberg and Schoenheimer in 1937 (Schoenheimer and Rittenberg, 1937), which represents one of the first uses of tracers to study metabolic pathways. However, limitations in the level of deuterium enrichment that can be safely achieved in humans and in the sensitivity of determination of enrichment in the metabolites synthesized have long restricted the usefulness of this method. These technical limitations have been overcome, however, and deuterated water can now be used to study both gluconeogenesis and lipid synthesis.
The basis for this method to measure gluconeogenesis is shown in figure 4 . Hydrogen (or deuterium) is incorporated in various positions of the glucose molecule during its synthesis. Incorporation on carbon 6 occurs during the transformation of pyruvate into phosphoenolpyruvate (Rognstadt, 1991). Thus, labeling in position 6 is representative of gluconeogenesis, except for gluconeogenesis from glycerol. Labeling on carbon 2 occurs during the cycling between glucose- 6 phosphate and fructose6 phosphate. Glucose from gluconeogenesis will be labeled but glucose from glycogenolysis will also be labeled since cycling between glucose- 6 phosphate and fructose- 6 phosphate takes place at a much higher rate than glucose production from glucose- 6 phosphate through glucose- 6 phosphatase activity. Therefore, the amount of deuterium bound to carbon 6 relative to that bound to carbon 2 provides a measure of the fraction of glucose formed via gluconeogenesis (Landau et al, 1995c). Landau et al (1995c) developed an elegant method for measuring low deuterium enrichments on carbons 2 and 6 of glucose by mass spectrometry. Using this method in normal subjects ingesting deuterated water in order to obtain an enrichment in plasma water of about $0.5 \%$, they were able to demonstrate during a $42 \mathrm{~h}$ fasting period a progressive increase of the contribution of gluconeogenesis to total glucose production from $35 \%$ (at $14 \mathrm{~h}$ ) to $69 \%$ (42 h).
Fig 4. Measurement of gluconeogenesis using deuterated water. Only the glucose originating from gluconeogenesis is labeled in position 6, while the glucose coming from glycogenolysis or gluconeogenesis is labeled in position 2 during the glucose- 6 phosphate - fructose- 6 phosphate cycle.

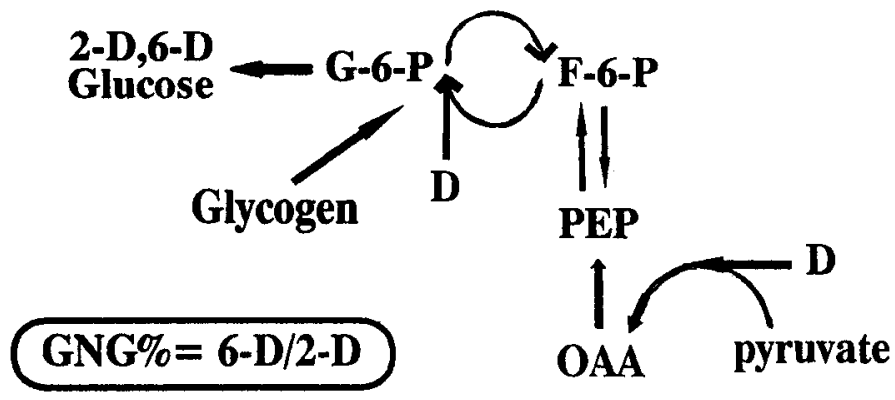


Table I. Results of measurements of the contribution (percentage) of gluconeogenesis, lipogenesis and cholesterol synthesis to the circulating pools of glucose, fatty acid triglycerides and plasma cholesterol in the control subjects.

Measurement method

Gluconeogenesis

$12 \mathrm{~h}$

$20 \mathrm{~h}$

$40-60 \mathrm{~h}$

\section{NMR}

(\%)

70

$-$
(\%)

$\begin{array}{ll}- & 2-4\end{array}$

(\% by day)

Cholesterol

synthesis

(\% by day)

\section{$-1$}

70

85

- n -
MIDA

(\%) $\mathrm{D}_{2} \mathrm{O}$

$(\%)$

$\begin{array}{lll}- & - & 30 \\ - & - & 55 \\ 85 & 65 & 70\end{array}$

55

70

$6-8$

3-4

- $\quad 3-4 \quad 3-5$

NMR: nuclear magnetic resonance; MIDA: mass isotopomer distribution analysis; $\mathrm{D}_{2} \mathrm{O}$ : deuterium incorporation from deuterated water. See Helierstein et al, 1991a,b; Landau et al, 1995b,c; Magnusson et al, 1991, 1992; Neese et al, 1993; Petersen et al, 1996; and Taylor et al, 1966.

The incorporation of deuterium in fatty acids and cholesterol during their synthesis is not only dependent on the deuterium enrichment of the body water and on the activity of the biosynthetic pathway but also on the average number of deuterium atoms that can be incorporated into fatty acids and cholesterol, given the existence of some isotope discrimination against deuterium versus hydrogen. This number was first found during in vitro studies to be 17 for palmitate and 20 for cholesterol (Lee et al, 1994b). Subsequent studies, however, found higher values (22 and 27 to 30 ) during in vivo biosynthesis (Lee et al, 1994a; Diraison et al, 1996). Deuterium enrichment in plasma water is measured by isotope ratio mass spectrometry (IRMS) or by a simpler gas chromatography-mass spectrometry method (Previs et al, 1996) when the enrichment is high enough. Knowing this enrichment and the average number of deuterium atoms that can be incorporated, one can calculate the deuterium enrichment that would be observed in palmitate or cholesterol if their only source was endogenous synthesis. Comparison with the actual value measured gives the contribution as a percentage of endogenous synthesis to the sampled pool of palmitate or cholesterol. This method has been used (Jones and Schoeller, 1990; Leitch and Jones, 1993; Cella et al, 1995) to measure lipogenesis and cholesterol synthesis in human subjects. In these studies, very low levels of deuterium enrichment in plasma water, and thus in fatty acids and cholesterol, were attained. The enrichment in the fatty acids and cholesterol had to be measured by IRMS, a tedious and time-consuming method. We have recently shown (Diraison et al, 1995) that a deuterium enrichment in plasma water of about $0.3 \%$ permits the measurement of fatty acid and cholesterol enrichment by gas chromatography-mass spectrometry, a much simpler technique. 
One main advantage of deuterated water is that it can be orally ingested and there is therefore no need for intravenous infusion. This makes this method particularly suitable for outpatient studies. Moreover, gluconeogenesis, lipogenesis and cholesterol synthesis can be measured simultaneously. A drawback, however, is the presence of excess deuterium in multiple metabolites for a period of several weeks or months (Taylor et al, 1966), thus preventing repetitive studies in the same subjects.

\section{CONCLUSION}

Several noninvasive methods are now available to study in vivo gluconeogenesis as well as lipogenesis and cholesterol synthesis in humans. Table I summarizes the main results obtained at the present time. These methods will be useful for studies of hormonal and nutritional control of liver metabolism in normal subjects as well as in pathological states such as obesity, diabetes and stress.

\section{REFERENCES}

Beylot M, Martin C, Laville M, Riou JP, Cohen R, Mornex $R$ (1991) Lipolytic and ketogenic flux in human hyperthyroidism. J Clin Endocrinol Metab 73, 42-49

Beylot M, David F, Brunengraber H (1993) Determination of the ${ }^{13} \mathrm{C}$ labeling pattern of glutamate by gas chromatography-mass spectrometry. Anal Biochem 212, 532-536

Beylot M, Soloviev MV, David F, Landau BR, Brunengraber $H$ (1995) Tracing hepatic gluconeogenesis relative to citric acid cycle activity in vitro and in vivo. $J$ Biol Chem 270, 1509-1514

Cella LK, Van Cauter E, Schoeller DA (1995) Diurnal rhythmicity of human cholesterol synthesis: normal pattern and adaptation to simulated "jet lag". Am J Physiol 269, E489-E498

Di Donato L, Des Rosiers C, Montgomery JA, David F, Garneau M, Brunengraber H (1993) Rates of gluconeogenesis and citric acid cycle in perfused livers, assessed with from the mass spectrometric assay of the ${ }^{13} \mathrm{C}$ labeling pattern of glutamate. J Biol Chem 268, 4170-4180

Diraison F, Pachiaudi C, Beylot M (1995) Mesure de la lipogenèse hépatique et de la synthèse de cholestérol à l'aide d'eau deuterée. $3^{e}$ Congrès de Nutrition, Lyon, France, 11-13 October

Diraison F, Pachiaudi C, Beylot M (1996) In vivo measurement of plasma cholesterol and fatty acids synthesis with deuterated water: determination of the average number of deuterium incorporated. Metabolism (in press)

Dugelay S, Yang D, Soloviev MV, Previs SF, Agarwal $\mathrm{KC}$, Fernandez CA, Brunengraber $\mathrm{H}$ (1994) Assay of the concentration and ${ }^{13} \mathrm{C}$ labeling pattern of phenylacetylglutamine by nuclear magnetic resonance. Anal Biochem 221, 368-373

Hellerstein MK, Neese RA (1992) Mass isotopomer distribution analysis: a technique for measuring biosynthesis and turnover of polymers. Am J Physiol 263, E988-E1001

Hellerstein MK, Greenblatt DJ, Munro HN (1986) Glycuroconjugates as non invasive probes of intrahepatic metabolism: pathways of entry of glucose into compartmentalized hepatic UDP-glucose during glycogen accumulation. Proc Natl Acad Sci USA 83, 7044-7048

Hellerstein MK, Christiansen M, Kaempfer S, Kletke C, Wu K, Reid JS, Mulligan K, Hellerstein NS, Schackleton CHL (1991a) Measurement of de novo lipogenesis in humans using stable isotopes. $J$ Clin Invest $87,1841-1852$

Hellerstein MK, Kletke C, Kaempfer S, Wu K, Schackleton CHL (1991b) Use of mass isotopomer distributions in secreted lipids to sample lipogenic acetyl CoA pool in vivo in humans. Am J Physiol 261, E479E486

Hellerstein MK, Wu K, Kaempfer S, Kletke C, Shackleton $\mathrm{CHL}(1991 \mathrm{c})$ Sampling the lipogenic hepatic acetylCoA pool in vivo in the rat. J Biol Chem 266 , 10912-10919

Hellerstein MK, Kaempfer S, Reid JS, Wu K, Schackleton CHL (1995) Rate of glucose entry into hepatic UDPG by the direct pathway in fasted and fed states in normal humans. Metabolism 44, 172-182

Hetenyi $G$ Jr (1982) Correction for the metabolic exchange of ${ }^{14} \mathrm{C}$ for ${ }^{12} \mathrm{C}$ in the pathway of gluconeogenesis in vivo. Fed Proc 41, 104-109

Hwang JH, Perseghin G, Rothman DG, Cline GW, Magnusson I, Petersen KF, Shulman GI (1995) Impaired net hepatic glycogen synthesis in insulin-dependent diabetic subjects during mixed meal ingestion. J Clin Invest 95, 783-787

James OM, Smith RL, Williams RT, Reidenberg M (1972) The conjugation of phenylacetic acid in man, subhuman primates and some non primate species. Proc $R$ Soc Lond [Biol] 182, 25-35 
Jones PJH, Schoeller DA (1990) Evidence for diurnal periodicity in human cholesterol synthesis. J Lipid Res 31, 667-673

Katz J (1985) Determination of gluconeogenesis in vivo with ${ }^{14} \mathrm{C}$ labeled substrates. Am J Physiol 248, R391R399

Kelleher JK (1986) Gluconeogenesis from labeled carbon: estimating isotope dilution. Am J Physiol 250, E296-E305

Kelleher JK, Masterson TM (1992) Model equations for condensation biosynthesis using stable isotopes and radioisotopes. Am J Physiol 262, E118-E125

Landau BR, Chandramouli V, Schumann WC, Ekberg K, Kumaran K, Kalhan SC, Wahren J (1995a) Estimates of Krebs' cycle activity and contributions of gluconeogenesis to hepatic glucose production in fasting healthy subjects and IDDM patients. Diabetologia $38,831-838$

Landau BR, Fernandez CA, Previs SF, Ekberg K, Chandramouli V, Wahren J, Kalhan SC, Brunengraber $\mathrm{H}$ (1995b) A limitation in the use of mass isotopomer distributions of measure gluconeogenesis in fasting humans. Am J Physiol 270, E18-E26

Landau BR, Wahren J, Chandramouli V, Schumann WC, Ekberg K, Kalhan SC (1995c) Use of $2 \mathrm{H}_{2} \mathrm{O}$ for estimating rates of gluconeogenesis. Application to the fasted state. J Clin Invest 95, 172-178

Large V, Odéon M, Beylot M (1994) Validation of the use of the labeling pattern of hepatic glutamate during $\left[{ }^{3-13} \mathrm{C}\right]$ lactate infusion to calculate citric acid cycle activity and gluconeogenesis. 2nd World Conference on Stable Isotopes in Nutritional and Metabolic Research, Rotterdam, the Netherlands, 4-7 July

Large V, Solovivev M, Brunengraber H, Beylot M (1995) Lactate and pyruvate isotopic enrichments in plasma and tissues of post-absorptive and starved rats. $A m$ JPhysio/ 268, E880-E888

Lee WNP, Guo ZK, Bergner EA (1992) Mass isotopomer pattern and precursor-product relationship. Biol Mass Spectrom 21, 114-122

Lee WNP, Bassilian S, Guo Z, Schoeller DA, Edmond J, Bergner EA, Byerley LO (1994a) Measurement of fractional lipid synthesis using deuterated water and mass isotopomer analysis. Am J Physiol 266, E372E383

Lee WNP, Bassilian S, Ajie HO, Schoeller DA, Edmond J, Bergner EA, Byerley LO (1994b) In vivo measurement of fatty acids and cholesterol synthesis using deuterated water and mass isotopomer analysis. Am J Physio/ 266, E669-E708

Leitch CA, Jones PJH (1993) Measurement of human lipogenesis using deuterium incorporation. $J$ Lipid Res 34, 157-163

Magnusson I, Schumann WC, Bartsh CE, Chandramouli V, Kumaran K, Wahren J, Landau BR (1991) Non invasive tracing of Krebs' cycle metabolism in liver. J Biol Chem 266, 6975-6984
Magnusson I, Rothman DL, Katz LD, Schulman RG, Shulman GI (1992) Increased rate of gluconeogenesis in type II diabetes mellitus. A ${ }^{13} \mathrm{C}$ nuclear magnetic resonance study. J Clin Invest 90, 1323-1327

Magnusson I, Rothman DL, Jucker B, Cline GW, Schulman RG, Shulman Gl (1994) Liver glycogen turnover in fed and fasted humans. Am J Physiol 266, E796$\mathrm{E} 803$

Neese R, Faix D, Kletke C, Wu K, Chang AC, Shackleton CHL, Hellerstein MK (1993) Measurement of endogenous synthesis of plasma cholesterol in rats and humans using mass isotopomer distribution analysis (MIDA). Am J Physiol 264, E134-E147

Neese RA, Schwarz JM, Faix D, Turner S, Letscher A, Vu D, Hellerstein MK (1995) Gluconeogenesis and intrahepatic triose-phosphate flux in response to fasting or substrate loads. Application of the mass isotopomer distribution analysis technique with testing of assumptions and potential problems. J Biol Chem 279, 14452-14663

Peroni O, Large V, Beylot M (1995) Measuring gluconeogenesis with $\left[2^{-13} \mathrm{C}\right]$ glycerol and mass isotopomer distribution analysis of glucose. Am J Physiol 269, 514-523

Peroni O, Large V, Odéon M, Beylot M (1996) Measuring glycerol turnover, gluconeogenesis from glycerol and total gluconeogenesis with $\left[2-{ }^{13} \mathrm{C}\right]$ glycerol: role of the infusion-sampling mode. Metabolism (in press)

Petersen KF, Price T, Cline GW, Rothman DL, Shulman Gl (1996) Contribution of net hepatic glycogenolysis to glucose production during the early post-prandial period. Am J Physiol 270, E186-E191

Previs SF, Fernandez CA, Yang D, Soloviev MV, David F, Brunengraber $H$ (1995) Limitations of the mass isotopomer distribution analysis of glucose to study gluconeogenesis. J Biol Chem 270, 19806-19815

Previs SF, Hazey JW, Diraison F, Beylot M, David F, Brunengraber $H$ (1996) Assay of the deuterium enrichment of water by acetylene. J Mass Spectrom (in press)

Roden $M$, Perseghin G, Petersen KF, Hwang $J H$, Cline GW, Gerow K, Rothman DG, Shulman Gl (1996) The roles of insulin and glucagon in the regulation of hepatic glycogen synthesis and turnover in humans. $J$ Clin Invest 97, 642-648

Rognstad R (1991) Estimation of gluconeogenesis and glycogenolysis in vivo using tritiated water. Biochem J 279, 971

Rothman DL, Magnusson I, Katz LD, Shulman RG, Shulman GI (1991) Quantiation of hepatic glycogenolysis and gluconeogenesis in fasting humans with ${ }^{13} \mathrm{C}$ NMR. Science 254, 573-576

Schoenheimer B, Rittenberg D (1937) Deuterium as an indicator in the study of intermediary metabolism. VI. Synthesis and destruction of fatty acids in the organism. J Biol Chem 114, 381-396 
Shulman RG, Brown TR, Ugenbil K, Ogawa S, Cohen SM, Den Hollanda JA (1979) Cellular applications of ${ }^{31 P}$ and ${ }^{13} \mathrm{C}$ nuclear magnetic resonance. Science 205, 160-166

Shulman Gl, Ladenson PW, Wolfe MH, Ringway EC, Wolfe RR (1985) Substrate cycling between gluconeogenesis and glycolysis in euthyroid, hypothyroid and hyperthyroid man. J Clin Invest 76, 757-764

Stromski ME, Arias Mendoza F, Alger JR, Shulman RG (1986) Hepatic gluconeogenesis from alanine: ${ }^{13} \mathrm{C}$ NMR methodology for in vivo studies. Magn Reson Med 3, 24-32

Taylor CB, Mikkelson B, Anderson JA, Forman DT (1966) Human serum cholesterol synthesis measured with the deuterium label. Arch Pathol 81, 213-230
Yang DW, Beylot M, Agarwal KC, Soloviev MV, Brunengraber $H$ (1993) Assay of the human liver citric acid cycle probe phenylacetylglutamine and phenylacetate in plasma by gas chromatography-mass spectrometry. Anal Biochem 212, 277-282

Yang DW, Previs SF, Fernandez CA, Dugelay S, Soloviev MU, Hazey JW, Agarwal KC, Levine WC David F, Rinaido P, Beylot M, Brunengraber $H$ (1996) Non-invasive probing of citric and cycle intermediates in primate liver with phenyl acetylglutamine. $A m$ J Physiol 270, E882-E889

Zhang Y, Agarwal KC, Beylot M, Soloviev MV, David F, Reider M, Anderson VE, Tserng KY, Brunengraber $H$ (1994) Non homogenous labeling of liver extramitochondrial acetyl-CoA. J Biol Chem 269, 11025 11029 